\title{
Kunsteorie en kunspraktyk: die kunste as 'n hermeneutiek-in-aksie
}

Bert Olivier

Departement Filosofie

Universiteit van Port Elizabeth

PORT ELIZABETH

\begin{abstract}
The present article sets out from Vaclav Havel's observation that there is a strong connection between good laste in art and a sensitivity towards others and the enviromment in the practical domain of life. This assenion is incrrogated along the lines of Habennas's ideal of communicative rationality by cxploring the sense in which the 'language' of art contributes to interpretive communication in the broad sense of the tem. Wittgenstein's concept of the plurality of language games is emploved in conjunction with the Husscrlian idea of the life-world to indicate the role of the arts in preserving the cognitive and moral-practical richness of this sphere. Two hermeneutic models - those of Schiller and Gadamer - are then outlined bricfly before concluding with a demonstration of their pertinence for the incepretation of a filmic artwork, viz. Arcand's Jesus of Montrcal.
\end{abstract}

\section{INLIEIDING}

In 'n onlangs gepublisecrde onderhoud met Time se Lance Morrow (1992:44-46) maak die gevierde dramaturg-skrywer, Vaclav Havel (tot onlangs en sedert 1989 president van Tsjeggo-Slowakye) die volgende opmerking:

\begin{abstract}
I have found that good taste, oddly cnough, plays an important role in politics. Why is it like that? The most probable reason is that good taste is a visible manifestation of human sensibility toward the world, environment, people. I came to this castle and to other governmental residences inherited from communism, and I was confronted with tasteless furniture and many tasteless pictures. Only then did I realize how closely the bad taste of former rulers was connceted with their bad way of ruling. I also realized how important good taste was for politics. During political talks, the fecling of how and when to convey something, of how long to speak, whether to interrupt or not, the degrec of attention, how to address the public, forms to be used not to offend someone's dignity and on the other hand to say what has to be said, all these play a major role. All such political behaviour relates to good taste in a broader sense. What 1 really have in mind is somcthing more than just knowing which tic to choose to match a particular shirt.
\end{abstract}

Die 'goeie smaak' waarvan Havel hier praat en wat volgens hom 'n waarneembare manifestasie van menslike gevoeligheid vir die omgewing en vir ander mense is, hou 
ideehistories verband met die smaakestetika van die $18 d e$ eeu, waar smaak breedweg gesproke as die subjektiewe korrelaat van 'n bepaalde eweredigheid, skoonheid of harmonie in die kunswerk of in die natuur figureer (Baumer, 1977:154-156), 'n tema wat nie binne die grense van die huidige artikel kan of noodwendig moet behandel word nie. Uit die res van die aanhaling is dit duidelik dat goeie smaak langs die weg van 'n soort sensitiwiteit vir die vereistes ten opsigte van geslaagde kommunikasie, vir Havel deel uitmak van wat in die idioom van resente kritiese teorie kommunikatiewe rasionaliteit heet. Breedweg gesproke het laasgenoemde begrip te make met die voorwaardes vir vrye, onverwronge intermenslike kommunikasie.

\section{DIE KUNSTE, KOMMUNIKASIE EN TAAL}

Wat het dit nou eintlik met die kunste as hermeneutiese praktyk (of praktiese hermeneutiek) te doen? Myns insiens meer as wat 'n mens met die eerste oogopslag mag vermoed. Of dit nou skone kunste, drama of musiek is - in ieder geval is daar sprake van ' $n$ interaksie van die een of ander aard, hetsy tussen persone as akteurs, of tussen 'n persoon en 'n medium of instrument waarmee of aan die hand waarvan in laaste instansie gekommunikeer word - nie slegs met ander mense soos 'n gehoor of toeskouers nie, maar ook in 'n sekere sin met die medium of instrument self in terme van die kommunikatiewe potensiaal daarvan. Elke skilder of beeldhouer het al die ervaring gehad, naamlik om nuwe, soms onverwagte moontlikhede in hul medium (byvoorbeeld olieverf, pastel, brons, marmer, beton) te ontdek, net soos 'n violis of pianis gedurende 'n musiekuitvoering in 'n intieme gee-en-neem-dialoog met sy/haar instrument verkeer. 'n Akteur ontdek gedurig nuwe interpretatief-kommunikatiewe moontlikhede ten opsigte van sy of haar liggaam, insluitend stemgebruik.

Die feit dat ek al bogenoemde gevalle as voorbeelde van kommunikatiewe interaksie bestempel, behoort nie as verrassend beskou te word nie. Sonder uitsondering figureer daar by elkeen ' $n$ interpretatiewe moment in samehang met 'n semiotiese dimensie, oftewel spesifieke tekenkomplekse wat onderworpe is aan interpretasie. En weer eens is dit nie verbasend nie, want in die breedste sin van die woord gaan dit telkens om taal.

Dit is immers nie net die gesproke woord wat kwalifiseer as taal nie. Bo en behalwe die sogenaamde 'natuurlike tale' soos Afrikaans, Engels, Xhosa, Duits, en so meer, kommunikeer ons deur middel van beelde, diagramme, gesigsuitdrukkings en gebare. $\mathrm{Na}$ bewering het Ludwig Wittgenstein sy vroeë 'prentteorie' van taal - dit wil sê die opvatting dat taal 'n logiese 'prent' van die wêreld is - laat vaar nadat die Italiaanse ekonoom, Piero Sraffa, eendag in 'n gesprek 'n gebaar gemaak het en Wittgenstein uitgedaag het om hom die feitelike toedrag van sake te wys waarvan sy gebaar'n logiese prent of beeld sou wees (Hartnack, 1965:48-49). Hierdie gebeurtenis het 
daartoe bygedra dat Wittgenstein sy vroeë taalfilosofie verwerp en in die plek daarvan 'n filosofiese taalpragmatiek geformuleer het. Volgens hierdie latere standpunt het taal nie slegs een, eksklusiewe, legitieme funksie nie, maar ontelbare gebruike, en repudieer hy sy eie vroeëre 'prentteorie' uitdruklik in hierdie verband. Wat meer is: taalgebruike - of wat hy noem taalspel (language games) - beliggaam verskillende lewensvorme (Wittgenstein 1976:19 e.v.), en waar 'n spesifieke taalspel of diskoers afwesig is, ontbreek daardie lewensvorm ook. 'n Kultuur sonder die taalspel van die wiskunde is eweneens sonder wiskundige praktyke; 'n kultuur waar 'n teatertaal ontbreek, beskik klaarblyklik nie oor 'n teater- of dramapraktyk nie, en so meer.

Wat veral treffend is omtrent Wittgenstein se selfkritiek (m.a.w. sy kritiek ten opsigte van sy vroeë bevoorregting van die representasiefunksie van taal in sy sogenaamde picture theory), is die feit dat hy dit as onregverdigbaar beskou om een van die veelvuldige funksies van taal uit te sonder as fundamenteel in verhouding tot die ander. (Richard Rorty se neopragmatiese verwerping van die foundationalist discourse van tradisionele epistemologie herinner 'n mens in hierdie opsig sterk aan die latere Wittgenstein). Taal word immers nie uitsluitlik gebruik om die wêreld te beskryf (m.a.w. te representeer) nie; ons maak beloftes in taal, ons gee bevele, rig versoeke, probeer ander oorreed, flikvlooi of probeer selfs verlei met taal; ons lieg of praat die waarheid, ons betuig ons medelye, spreek vertroue of wantroue uit, en nog vele ander dinge. Kort en kragtig gestel: ons kommunikeer. Kommunikasie is onontbeerlik vir menslike bestaan, en hoe meer veelvuldig en veelfasettig die kommunikasievorme in 'n spesifieke kultuur, hoe groter en ryker die verskeidenheid van lewensvorme in daardie kultuur. Ek glo nie dat dit onakkuraat sou wees om die verdere stelling te maak nie, naamlik dat die aanwesigheid van'n ryk uiteenlopendheid van taalpraktyke verder blyke gee van 'n groot aantal perspektiewe op of interpretasies van menslike bestaan. In 'n (hipotetiese) situasie waar slegs een taalpraktyk as legitiem beskou word - soos byvoorbeeld "Newspeak" in Orwell se 1984 - vind 'n reduksie of verarming van menslike bestaan plaas wat of vrugbare teelaarde vir, of uitdrukking van reeds bestaande totalitêre praktyke verteenwoordig.

\section{TAALPLURALISME EN LEEFWêRELD}

Weer eens: wat het dit met die kunste te doen? Ek het vroeër reeds na die kommunikatiewe funksie van die kunste verwys, en die refleksie oor Wittgenstein se taalspelfilosofie het pas die onreduseerbare verskeidenheid van taalpraktyke aan die lig gebring, sowel as die gepaardgaande implikasie, naamlik dat die bevoorregting van enige taalpraktyk of diskoers (insluitend wetenskaplike en tegnologiese diskoerse) ten koste van ander op wederregtelike hegemonie sou neerkom. Uit watter oogpunt kan ek dit 'wederregtelik' noem? Beteken so 'n oordeel nie eweneens 'n arbitrêre 
verheffing van 'n kontingente kulturele en linguistiese verskeidenheid tot normatiewe vlak nie? Indien 'n gegewe diskursiewe en kommunikatiewe pluralisme die enigste grond was waarop daar bedenkinge uitgespreek word oor die verabsolutering van bepaalde diskursiewe praktyke, sou dit inderdaad 'n anomalie wees om een feitelike toedrag van sake (taalpluralisme, in die breë sin) prioriteit te gee bo 'n ander (die neiging tot hegemonie van 'n bepaalde stel diskoerse met sekere gemeenskaplike kenmerke).

Ek meen nietemin dat 'n pluralistiese taalpraktyk verdedigbaar is op normatiewe, niearbitrêre gronde, en dat die onmisbare funksie van die kunste as hermeneutiese oftewel diskursief-interpretatiewe praktyke langs hierdie weg gedemonstreer kan word. Vaclav Havel is vroeër aangehaal waar hy stel dat wat hy 'goeie smaak' noem die uiterlike teken is van 'n ontvanklikheid en sensitiwiteit vir andere en vir die omgewing. Dit impliseer 'n houding van bevestigende integrasie, maar tegelyk ook differensiasie ten opsigte van die unieke aard en behoeftes van self, ander en natuur. Anders gestel: Havel vestig die aandag op die plurale struktuur van die wêreld waarin ons leef, asook, by implikasie, op die noodsaaklikheid om hermeneuties (interpretatief) toegerus te wees om die eie-aardige eise en behoeftes van ander en van die natuur te verstaan en te eerbiedig. En van die leefwêreld gepraat: 'n mens kan nie nalaat om aan Edmund Husserl - wat dit gemunt het - te dink wanneer die begrip gebesig word nie. Dit was immers Husserl wat in sy laaste groot werk (Husserl, 1984:104-105) aangetoon het dat die leefwêreld (Lebenswelt) die onmisbare basis voorsien vir die wetenskappe, wat bloot tematiserings van die een of ander leefwêreldlike gegewe uitmaak. (So is die fisika byvoorbeeld die sistematiese tematisering van die fisiese as primordiale leefwêreldlike gegewe, die sosiologie van die sosiale, ensovoorts.) Vanuit hierdie oogpunt is die leefwêreld, in al die genuanseerde verskeidenheid daarvan, die sfeer waarin daar ' $n$ primordiale vervlegtheid van onderskeibare praktyke en taalgebruike bestaan. Is dit verregaande om hierdie gedifferensieerde lewensfeer, met al sy onreduseerbare uiteenlopendheid, as normatief te beskou vir menslike bestaan en dus vir 'n menswaardige bestaanswyse? Ek glo nie, ofskoon 'n mens behoort by te voeg gedagtig aan Habermas (1988:306) se kritiese opmerking, naamlik dat Wittgenstein se taalpluralisme die wêreld laat staan soos dit is - dat die leefwêreld steeds onderworpe bly aan die eis om ' $n$ 'beter' of meer menswaardige lewe moontlik te maak. Dit is immers nooit die geval dat die ideaal van onverwronge intermenslike kommunikasie op enige gegewe tydstip volledig gerealiseer word nie.

\section{DIE BEMIDDELENDE FUNKSIE VAN DIE KUNSTE}

Ook Habermas praat afkeurend van die tendens, so eie aan die moderne era, om die leefwerreld toenemend met ekonomiese en administratiewe imperatiewe te 'koloniali- 
seer' (Habermas, 1981:18); met ander woorde, om die lewensfeer waar kognitiefinstrumentele, moreel-politiese en estetiese momente met mekaar ineengestrengel is, te laat verbrokkel deur dit te meet aan die gespesialiseerde eise van slegs een lewensfaset, naamlik die kognitief-instrumentele of -tegniese. Heidegger het waarskynlik dieselfde bedreiging in gedagte waar hy waarsku om die wese van die tegnologie (meer spesifiek: Ge-stell - die opkommandering van alles vir maksimale benutting deur die mens) nie as die enigste manifestasie van Syn te beskou nie (Heidegger, 1977:27-35), aangesien daar ook ander 'plekke' bestaan waar 'n mens toegang tot die Syn van menswees, van die natuur, en so meer kan verkry. En dit bring ons terug by die kunste, omdat kuns vir Heidegger juis een van hierdie alternatiewe 'plekke' van synsonverborgenheid is wat ons in staat stel om opnuut ons menswees interpretatief te ontdek. Hierdie gedagte kan verder ontwikkel word aan die hand van Habermas se opvatting van kuns en filosofie in die konteks van 'n gefragmenteerde hedendaagse kultuur.

Habermas (Ingram, 1991:67-68) skryf eweneens aan die kunste 'n besondere funksie toe ten opsigte van die geïntegreerdheid van menslike bestaan. Volgens hom behoort estetiese rasionaliteit nie slegs toeganklik te wees vir deskundiges soos professionele kunstenaars en kunskritici nie, maar behoort gewone mense - die publiek - via die kunste te deel in 'n waarheidservaring wat opnuut die kognitiewe, die moreelnormatiewe en die estetiese met mekaar integreer. Wat hierdie funksie van die kunste betref, kan 'n mens dit op ' $n$ wyse tipeer wat analoog is aan die bemiddelende rol wat Habermas vir die filosofie voorsien in die diskursief-gekompartementaliseerde moderne kultuur. Waar die moderne wetenskap en tegniek, positiewe reg en posttradisionele etiek, en derdens outonome kuns en geïnstitusionaliseerde kunskritiek die hoofmomente uitmaak van die gedifferensieerde rasionaliteit wat eie is aan moderniteit, loop hulle volgens Habermas (1988:312) gevaar om geheel en al geïsoleerd te raak van alledaagse kommunikasie, tensy die filosofie in die rol van interpreteerder, tussen hulle en die verarmde leefwêreld kan bemiddel (Habermas, 1988:313). Myns insiens is die kunste in die ideale posisie om juis 'n soortgelyke hermeneuties-bemiddelende funksie te verrig. Habermas (1988:313) het blykbaar ook so iets in gedagte waar hy van postmoderne kuns sê:

It is characterized by a strange simultancity of realistic, politically committed schools, on the one hand, and authentic followers of that classical modernism to which we owe the crystallization of the specific meaning of the acsthelic, on the other. In realistic and politically committed art, elements of the cognitive and the moral-practical come into play once again but at the level of the wealth of forms unloosed by the avant-garde. To that extent they act as agents of mediation. Counterdevelopments like these, it secms, mitigate the rigid compartmentalization of reason, pointing to reason's unity. In this regard, everyday life is a more promising medium for regaining the lost unity of reason than are today's expert cultures or yesteryear's classical philosophy of rcason. 
Op dieselfde noot sou ek argumenteer dat die kunste 'n belangrike medium is vir die behoud, en in vele opsigte die herwinning van (verlore) kognitiewe sowel as moreelpraktiese perspektiewe wat onmisbaar is vir die interpretasie van menslike bestaan in die volle leefwêreldlike omvang en potensieel ryk-geskakeerdheid daarvan. Hoe so iets moontlik is, kan kortliks verduidelik word aan die hand van twee denkskemas, onderskeidelik geformuleer deur Schiller en Gadamer.

\subsection{Die kunshermeneutiek by Schiller en by Gadamer}

In sy Briewe oor die estetiese opvoeding van die mensdom (geskryf 1794-95) formuleer Schiller (1981) een van die vroegste weergawes van wat bekend is as die tese van moderne kulturele vervreemding (vgl. Megill, 1985:13). In teenstelling met die antieke Grieke, wat vorm en inhoud, verbeelding en rede met mekaar verenig het, is die moderne mens volgens Schiller vanweë kultuurontwikkeling 'n verdeelde, vervreemde wese. Die aangewese geneesmiddel, so redeneer hy verder, is die kuns, waarin die speeldrif (Spieltrieb) na vore kom. Laasgenoemde is ' $n$ impuls wat 'n bemiddelingsfunksie vervul ten opsigte van twee fundamentele drifte, naamlik die sinlike drif (sinnliche Trieb) wat aan verandering of wording ten grondslag lê, en die vormdrif (Formtrieb) wat eenheid of syn bevorder. Anders gestel: volgens Schiller bewerkstellig kuns die nodige balans tussen die lewens- en gevoelgerigte sinlike drif enersyds, en die formeel-sedelik gerigte vormdrif andersyds, deurdat die speldrif in en deur die kuns 'lewende vorm' tot vergestalting bring. Sodoende, in die ervaring wat deur die kunste moontlik gemaak word, word die vervreemde mens - wat gebuk gaan onder die skeuring van gees en sinlikheid - opnuut die geleentheid gebied om 'n geïntegreerde selfbegrip te ontdek.

Die hermeneutiese denkmodel van Gadamer (o.a. 1982) vul die leemtes in dié van Schiller goed aan, spesifiek met betrekking tot wat hierbo as selfbegrip bestempel is. Alle verstaan en interpretasie is per slot van sake selfverstaan of dra daartoe by. Gadamer bevry nie alleen die kuns van die ietwat subjektiwistiese moment, wat Schiller die speeldrif noem, deur spel as 'n dinamiese struktuurelement van kunswerke self te tipeer nie, maar spesifiseer die verstaanproses verder op 'n wyse wat geredelik aan die hand van kunservaring en -interpretasie gedemonstreer kan word.

Gadamer (1982:274-275) onderskei drie interafhanklike struktuurmomente in die verstaangebeure, te wete verstaan, interpretasie (wat die eksplisiet-maak van verstaan verteenwoordig) en toepassing (Eng. application, wat die konsekwensies van 'n interpretasie vir die interpreteerder se unieke situasie artikuleer). Dit is veral in laasgenoemde moment dat die mate waarin verstaan onvermydelik selfverstaan impliseer, na vore kom. Hierdie faset van die hermeneutiese ervaring naamlik toepassing, vestig ook die 
aandag op wat Gadamer die tydgenootlikheid (Eng. contemporaneity) van die kunswerk noem (Gadamer 1982:108-114). Dit beteken die kenmerkende eienskap van kunswerke - literêr, musikaal, dramaties, visueel, en so meer - om deur verskillende geslagte en in verskeie historiese eras op soms uiteenlopende wyses geïnterpreteer te word sonder om enige relevansie in die proses in te boet.

\section{INTERPRETASIE EN TOEPASSING: ARCAND SE JESUS OF MONTREAL}

Vervolgens sal ek probeer om bondig te demonstreer hoe die verstaan en interpretasieproses in terme van bogenoemde hermeneutiese model in die geval van (die ervaring van) 'n besondere kunswerk 'werk' - 'n benaderingswyse wat terselfdertyd lig behoort te werp op die bewering dat die kunste 'n hermeneutiek-in-aksie verteenwoordig. My keuse val hier op 'n filmiese kunswerk - Denys Arcand se Jesus of Montreal - maar dit sou net sowel 'n drama, 'n opera, 'n skildery of 'n simfonieuitvoering kon wees. (Kyk ook in hierdie verband Olivier, 1984 en 1987.) My bespreking van genoemde rolprent sal uiteraard bondig wees.

Die verhaal wat in Arcand se Jesus of Montreal ontplooi, sentreer rondom die 'modernisering' van die passiespel wat gereeld deur die Rooms-Katolieke gemeente van Vader Leclerc in Montreal, Kanada, opgevoer word. Die persoon aan wie hy hierdie taak opdra, is die dertigjarige akteur, Daniel Coulombe, wat na etlike jare se afwesigheid na Montreal terugkeer. Daniel voer sy modernisering van die passiespel uit met behulp van resente argeologiese gegewens wat 'n revolusionêre hersiening van die identiteit van Jesus suggereer - so revolusionêr dat Vader Leclerc na die eerste opvoering woedend vir Daniel vra of hy "van sy sinne beroof is", ten spyte van die feit dat die gehoor, wat die akteurs van plek tot plek in die ontvouing van die buitelugopvoering volg, klaarblyklik daardeur aangegryp is. Dit is in so 'n mate die geval dat 'n vrou uit die gehoor, net na die Talita Kumi-toneel, die akteur (Daniel) wat Jesus se rol vertolk, om die nek val met die uitroep: "Jesus, ek kan nie sonder u leef nie". Haar 'opheffing van ongeloof' is so volkome dat die dramatiese handeling vir haar werklikheid word: die momenteel stomgeslane akteur word vir haar Jesus.

Dis egter nie slegs in die onmiddellike omgewing van die opvoering dat die dramatiese kunswerk (op kenmerkend postmodernistiese wyse) as 't ware sy eie grense oorspoel nie. Ook Daniel se persoonlike lewe neem die kontoere van Jesus se lewe aan: die verstaangebeure soos deur Gadamer beskryf, vind sy vergestalting in die wyse waarop Daniel Coulombe se interpretasie van die Christuspassie intra-filmies op sy eie lewe 'toegepas' word. Net soos Jesus voor hom, raak hy in onguns by die amptenare van die gevestigde kerk van die tyd; net soos die historiese Jesus jaag hy diegene (verteenwoordigers van die reklamewese) wat die tempel (in hierdie geval die menslike liggaam) 
ontheilig, weg en gooi die tafels met hul duur toerusting daarop, om. Net soos Jesus voor 'n ietwat besluitelose Pontius Pilatus verskyn het, word hy voor 'n magistraat gedaag wat so oorbluf word deur die kinderlik-onskuldige Daniel dat hy die hulp van 'n staatpsigoloog inroep om hom te adviseer. Weer eens: waar Christus volgens die evangelie deur die duiwel versoek is met die belofte van 'n wêreldse beloning, word Daniel Coulombe deur 'n bekende regsgeleerde cum agent verseker dat hy die stad (by implikasie die wêreld) kan besit indien Daniel sy talent aan hom, die regsgeleerde, as sy agent sou toevertrou. Dieselfde Mephistopheles-figuur is aan die einde van die filmnarratief byderhand om die herinnering aan Daniel se selflose nederigheid te ondermyn met die idee van 'n Daniel Coulombe-gedenkteatervereniging - soos ons uit die film leer, is institusies histories altyd sterker as individue.

Die mees treffende (en skokkende) aktualisering van die Christuspassie in Daniel se lewe is egter die feit dat hy ook, soos Jesus voor hom, aan die kruis sterf - wanneer'n man uit die gehoor per ongeluk, tydens 'n worsteling met 'n sekuriteitswag wat die opvoering in opdrag van die Kerk wou stopsit, die swaar houtkruis met Daniel en al omstamp sodat dit bo-op die tenger akteur val. Hy sterf egter nie onmiddellik nie, maar eers later in die teater by die Joodse hospitaal - 'n betekenisvolle gegewe - nadat die vertragende burokrasie by die oorvol Rooms-Katolieke hospitaal sy spoedige mediese behandeling verhoed het. Daar is selfs 'n toneelsekwensie waar die sterwendlydende Daniel saam met Constance (die Mariafiguur in die film) en Mireille ('n moderne verpersoonliking van Maria Magdalena) met die roltrap na die 'onderwêreld' van die moltrein-stasie afdaal, waar opvallend ongelukkige mense rondstaan. En die wederopstanding vind sy tydgenootlike ekwivalent in die wyse waarop Daniel se dertig jaar oue hart nuwe lewe aan 'n hartoorplantingpasiënt besorg en sy oë 'n blinde vrou weer laat sien. Die film eindig met die passiespel-kruis afgeteken teen die ligte van Montreal in die agtergrond: 'n aangrypende visualisering van Bonhoeffer se gedagte dat Christus aanwesig is waar daar lyding is.

Uit hierdie beknopte samevatting van Arcand se film behoort reeds te blyk in watter mate dit, in Gadameriaanse terme, die Jesusverhaal se tydgenootlikheid konkreetperseptueel demonstreer. Die intra-filmiese toepaslikheid van die 'waarheid' van Jesus vir Daniel Coulombe - die 'dialoog' of wisselspel, sou 'n mens kon sê, tussen die passiespel en sy eie lewe - stem verder ooreen met die wyse waarop die film via die kontemporêre integrasie van die Jesusverhaal 'n appèl rig tot elke lid van die filmgehoor ten opsigte van die betekenis en toepaslikheid wat dit vir daardie besondere persoon het. Anders gestel: Arcand se interpretasie van Jesus as 'lewende vorm' vra van die gehoor om langs die weg van die hermeneutiese ervaring van die filmnarratief hul eie interpretasie van Jesus te artikuleer. Per slot van rekening is ware interpretasie nooit - soos Gadamer (1982:147-150) tereg aantoon - blote rekonstruksie van die wêreld waarin 'n teks of kunswerk (in hierdie geval die Jesusverhaal) ontstaan 
het nie, maar 'n integrasie van daardie wêreldhorison met die betekenishorison van die interpreteerder. Dit beteken in laaste instansie dat hierdie filmkunswerk, net soos ander kunswerke, bemiddelend funksioneer om 'n komplekse kognitief-moreel-estetiese en (dikwels ook) religieuse ervaring by die gehoor te aktiveer.

\section{TER AFSLUITING}

Hieruit behoort duidelik te wees dat 'n mens hier nie met blote estetisisme te make het nie. Die aanvanklike benutting van Havel se stelling oor die rol van 'goeie smaak' by kommunikasie kon moontlik die verwagting geskep het dat daar afgestuur word op 'n sodanige estetisisme, oftewel 'n tipe leë formalisme, sonder enige praktiese konsekwensies. In teenstelling hiermee het die ondersoek egter aan die lig gebring dat die kommunikatiewe funksie van smakk (dit wil sê soos Havel die begrip gebruik) juis te make het met die oorskryding of deurbreking van diskursiewe grense - nie alleen tussen mense en tussen verskillende rasionaliteitsfere nie, maar ook tussen 'estetiese' werke (d.w.s. kunswerke) en toeskouers langs die weg van 'n omvattende hermeneutiese ervaring. In hierdie sin kan die kunste in die algemeen as 'n hermeneutiek-inaksie bestempel word.

\section{BIBLIOGRAFIE}

BAUMER, F.L. 1977. Modern European Thought. London : Collier Macmillan.

GADAMER, H-G. 1982. Truth and Method. Transl. Barden, G. \& Cumming, J. New York : Crossroad. HABERMAS, J. 1981. The Dialectics of Rationalization - An Interview. Telos, 49:5-31.

HABERMAS, J. 1988. Philosophy as Stand-in and Interpreter. (In Baynes, K., Bohmann, J., \& McCarthy, T. eds. After Philosophy End or Transformation? Cambridge, Mass. : MIT Press. pp. 2\%-315.)

HARTNACK, J. 1965. Wittgenstcin and Modern Philosophy. Transl. Cranston, M. London : Methuen.

HAVEL, V. 1992. I Cherish a Certain Hope. Intcrview by Lance Morrow. Time: 45-46, Aug. 31.

HEIDEGGER 1977. The Question Concerning Technology and Other Essays. Transl. Lovit, W. New York : Harper Torchbooks.

HUSSERL, E. 1984. The Crisis of European Sciences and Transcendental Phenomenology. Transl. Carr, D. Evanston : Northwestern University Press.

INGRAM, D. 1991. Habermas on Acsthetics and Rationality: Completing the Project of Enlightenment. New Geman Critique, 53:67-103.

MEGILl, A. 1985. Prophets of Extremity. Nictzsche, Heidegger, Foucault, Derrida. Bcrkeley : University of California Press.

OLIVIER, G. (Bert) 1984. The Art of the Cinema. Standpunte, 171:15-21.

OLIVIER, G. (Bcrt) 1987. Art and Transformation. Suid-Afrikaanse Tydskrif vir Wysbegeente, 6(1):16-23.

SCHILLER, F. 1981. On the Aesthetic Education of Man - in a Serics of Lelters. Transl. Sncll, R. Ncw York : Frederick Ungar Publishing Co.

WITTCiENSTEIN, L. 1976. Philosophical Investigations. Transl. Anscombe, G.E.M. Oxford : Basil Blackwell. 
